\title{
Um apontamento à visão de Vilém Flusser sobre a escrita de roteiros ante a minissérie Hoje é dia de Maria
}

\section{Luis Roberto Arthur de Faria}

Doutor; Universidade Estadual de Campinas, Campinas, SP, Brasil. lafarialuis11@gmail.com

\begin{abstract}
Resumo
O presente trabalho baseia-se em duas obras do filósofo Vilém Flusser, A escrita: há futuro para a escrita? (2010) e $O$ universo das imagens técnicas (2012), para debater a produção de roteiros a partir da perspectiva do filósofo sobre $\mathbf{o}$ ato de escrever e a criação de imagens técnicas. $O$ encontro entre essas duas obras permite considerar que os roteiros constituem um gênero textual voltado à programação dos pensamentos e comportamentos dos sujeitos. Como possibilidade de linha de fuga a essa disposição programadora, apresenta-se um trecho de roteiro da minissérie Hoje é dia de Maria (2005), escrita por Luís Alberto de Abreu e Luiz Fernando Carvalho, a partir de original de Carlos Alberto Soffredini . O confronto entre esse trecho de roteiro e o debate entre as obras de Flusser permite afirmar a possibilidade de escrever um texto para a mídia televisiva como um objeto capaz de transcender essa disposição programadora dos sujeitos. Assim, sugere-se que há roteiros que podem reprogramar os sujeitos, configurando estranhamentos que os levem a refletir sobre o que é dito na obra ou ao que assistem.
\end{abstract}

\section{Palavras-chave}

Flusser. Roteiro. Escrita. Minissérie. Hoje é dia de Maria.

\section{Introdução}

Vilém Flusser, filósofo tcheco naturalizado brasileiro, em seu livro A escrita: há futuro para a escrita? (FLUSSER, 2010), considera o ato de escrever uma forma de organizarmos, em nosso pensamento, o mundo que nos rodeia. É um trabalho de desenvolvimento da consciência humana. Nessa visão, o ser humano, no estágio anterior à invenção da escrita, teria vivido diretamente no mundo das imagens, chamadas por Flusser 
(2010) de imagens naturais. A invenção da escrita teria servido, então, para a busca de compreensão da realidade, já que não conseguimos captar o todo das imagens que se nos afiguram no contato com o real. Nesse raciocínio, o ser humano passou a significar o mundo para poder compreendê-lo.

Com o desenvolvimento das tecnologias eletrônicas de comunicação, há a exponenciação da quantidade de informações dadas via textos escritos. Porém, para Flusser (2010), por causa do desenvolvimento da tecnologia, os textos escritos voltam a tornar-se imagens, especialmente porque a escrita no computador é virtual, mediada pelo toque do teclado. A escrita, assim considerada, produziria imagens, as quais Flusser, em outra obra, O universo das imagens técnicas: elogio da superficialidade (2012), chama de imagens técnicas. Nesse livro, o autor discute basicamente o que são essas imagens técnicas. Para tanto, estabelece um contraponto às imagens que chama de tradicionais. Estas seriam processadas na mente da pessoa, numa transformação do mundo concreto em abstração, que pode ser semiotizada. Para tanto, o ser humano arranharia essas imagens processadas em sua mente, transformando-as em linhas de representação, o que ele diz ser o processo da escrita.

Já as imagens técnicas seriam aquelas processadas em máquinas criadas pelo ser humano, em aparelhos-operadores, tendo como exemplo os computadores. Os textos produzidos nessas máquinas seriam uma reconstituição da abstração que ocorre na mente das pessoas. Isso quer dizer que são imagens geradas a partir da abstração das imagens concretas. Uma imagem técnica aconteceria num estágio terceiro: o ser humano observa o mundo, abstrai-o em sua mente e o reproduz textualmente; ao fazer isso em uma máquina como um computador, processa esse texto em um campo virtual que produz novas imagens.

Flusser (2012), ainda, diz que o que conta em relação às imagens técnicas é o significante, pois elas semiotizam apenas caracteres informativos, e não explicativos, que permitem a compreensão do mundo - muitas pessoas acessam informações hoje por sistemas informatizados, mas não necessariamente compreendem-nas em seu contexto. As imagens irradiadas não necessariamente mostram algo que realmente aconteceu. Elas têm a intenção de formar massas ligadas aos aparatos técnicos de programação. Nesse sentido, a programação - televisiva, de computadores - evidencia a situação de programar os comportamentos e pensamentos. A lógica é a da cultura de massas.

A questão da cultura de massas é aprofundada a partir de uma visão hegeliana por Flusser. Segundo o autor (FLUSSER, 2012), as imagens irradiadas pelos media resolveriam o conflito da consciência infeliz, ideia segundo a qual as pessoas viveriam em constante 
tensão entre sair ao mundo, estabelecer vínculos e ser potencialmente questionadas em suas atitudes e recolher-se; e perder o que ocorre no mundo, concentrando-se em si próprias, muitas das vezes autoquestionando-se. A tensão, daí, derivaria essa infelicidade da consciência. As imagens midiáticas, então, criariam uma situação de dispersão e de divertimento das massas, que se tornariam inconscientes, de pensamentos $\mathrm{e}$ comportamentos automatizados, mas dentro de um sonho coletivo irradiado.

As imagens técnicas seriam, ainda, para Flusser (2012), terminais de raios que partem de feixes de raios sincronizados - que o autor chama fascistas, já que a palavra vem do italiano fascio, que significa feixe. Esse fascismo, nesse sentido, seria responsável por estruturar a sociedade da informática, já que os centros irradiadores dos feixes ocupariam o centro da sociedade. Esses centros irradiadores é que construiriam redes que programariam os pensamentos e os comportamentos sociais: redes de TV, cadeias de cinema, a Internet.

Combater a força desses centros irradiadores fascistas seria por meio de feixes transversais, antifascistas. Seria um modo de engajamento político que procuraria modificar a estrutura desses feixes sincronizados em rede. Esse engajamento político não se dirigiria contra as imagens, mas estaria como força contrária nascida do próprio universo das redes. Os fautores desse processo seriam pessoas voltadas ao trabalho com a imagem, como cineastas, programadores, entre outros.

É nesse contexto, de predomínio de imagens técnicas, retornando à questão debatida em A escrita: há futuro para a escrita? (FLUSSER, 2010), que os roteiros de cinema, de TV e de outras mídias estariam inseridos. Roteiros, para Flusser (2010), seriam escritos visando a uma produção técnica e, portanto, não se prestariam a ser produtos desenvolvedores da imaginação criativa, e sim, de imagens técnicas, que serviriam à lógica da programação, criadora de massas de consciência entorpecida. Pelo exposto, parece que o filósofo desdenha da produção de roteiros cinematográficos, colocando-os em um patamar mais baixo na escala de produção criativa humana.

Duas são as propostas deste artigo. A primeira é não admitir essa visão, pois Flusser, embora considere os roteiros produtos menos nobres, em verdade, deseja que autores deem valor ao ato de escrever roteiros, que o enobreçam; esse filósofo procura, em verdade, a valorização daquilo que se escreve, a valorização do pensamento por meio da escrita. 0 subtítulo do livro A escrita é há futuro para a escrita?, e coloca o alerta de analisarmos a questão do domínio das imagens técnicas, que pode tornar a escrita uma atividade que não teria futuro, face o predomínio do interesse pelas imagens técnicas. 
A outra proposta é demonstrar, por meio de um pequeno trecho de roteiro televisivo, da minissérie Hoje é dia de Maria, de Luís Alberto de Abreu e Luiz Fernando Carvalho (2005), que roteiros podem estruturar-se no combate ao fascismo massificador da irradiação de imagens técnicas pelas redes de comunicação. A análise desse roteiro demonstrará que o texto apresenta sutilezas que, embora tenha sido construído para a TV, um espaço de comunicação para a grande massa, tencionam criar espaços para uma espécie de reprogramação dos pensamentos e comportamentos.

\section{Flusser, escrita e semiose}

Para Flusser (2010), em A escrita: há futuro para a escrita?, o ato de escrever é o rompimento da imagem natural no sentido de se organizar um sistema linear. A imagem natural é arranhada e torna-se signo por meio da escrita, pois esse recurso operacional serve para possibilitar a comunicação. A escrita, para ele, como diz Boccara (2014), é iconoclasta, e, por isso, quando se escreve, rasga-se a imagem natural, que é alinhada em tiras, estabelecendo-se uma nova dimensionalidade para o pensamento, que se pode chamar de unidimensionalidade linear. Tal unidimensionalidade serve para que se alinhe o pensamento, colocando-o em trilhos: organizam-se combinações de palavras (sinais gráficos, por Flusser, podendo ser chamados de signos na Semiótica) dentro de regras sintáticas (os alinhamentos, ou trilhos) para que se organize o código, buscando daí significações que façam com que ele seja compartilhado; para que haja comunicação, enfim.

Escreve-se porque e quando se assume uma consciência histórica. Escreve-se porque se desejam reter os fatos na consciência; se não há retenção, a imagem rasgada esvai-se, perde-se, não permanece. A matéria possui uma continuidade que a escrita rasga, tornando-a descontínua. Descontinua-se a imagem natural da matéria, ou do objeto, para que se possa apreender o mundo, já que não se pode captar o todo de uma continuidade pelo movimento dos olhos. Capta-se o mundo em partes por meio do olhar, e pela escrita essa tarefa ocorre como em rasgos, em tiras, cuja descontinuidade tenta-se colocar em trilhos para que se organize o pensamento; não só para isso, mas também para que se oriente em direção ao outro. Escreve-se em uma tensão: há um movimento para dentro, que faz as pessoas refletirem sobre o que escrevem, e outro para fora, para o outro. Escreve-se, ou deve-se escrever, num estado de atenção, direcionado, organizativo, consciente, para que as mensagens comuniquem e, de certa forma, permaneçam, dentro dessa lógica desse estado de tensão considerado. 
Pode-se considerar, nesse raciocínio, que escrever é a negação da tendência natural de todos os objetos do mundo objetivo incorrer em situações mais prováveis, ou, como Flusser (2010) mesmo sugere, de alta entropia. Isso significa que quanto mais informativo um objeto, mais improvável ele é, e mais baixa é sua entropia. Flusser (2010) diz que as primeiras formas de escrita perpetuaram-se, e, assim, comunicaram, porque seu caráter informativo era baseado num alto fornecimento de energia sobre um sistema no qual se colocou um nível informacional. Assim, quando se inscrevia algo em placas de madeira ou de barro, como faziam, por exemplo, os mesopotâmios, dispendia-se de grande energia para se riscarem as placas com os cinzéis; criava-se um sistema improvável, de altíssima entropia, que se perpetuou. Aliás, inscrever é in-scribere, ou seja, riscar dentro de algo. Trata-se claramente de um processo dialético, transformacional, em que a matéria original serve como elemento fautor de um processo de culturalização. Assim, inscrever é um processo de perpetuação da informação, que é o descontinuar das imagens naturais do mundo, num processo de reflexão sobre o mundo.

Aos poucos, o ato de inscrever foi sendo substituído pelo ato, primeiro, de sobrescrever: com um pincel ou uma pena, e, utilizando-se de tinta, aplica-se a escrita em superfícies, o que torna o trabalho mais rápido, contrariamente aos trabalhos de inscrição, que demandavam mais tempo - aliás, o trabalho de escrita por uso de tinta, Flusser (2010) chama-o de documental, de instrução, como o dos monges copistas na Idade Média, já que é feito em pergaminhos ou folhas de papel, ao contrário do trabalho de inscrição dos antigos, que é por ele considerado monumental, de devoção, de contemplação de divindades. Aos poucos, novos aparatos foram surgindo na tarefa de escrita: a máquina de escrever, que demarcava uma impressão mediada numa folha de papel por meio do choque de um tipo numa fita com tinta que, por sua vez, demarcava uma letra; e o computador, com os processadores de texto, além dos aparelhos móveis, por meio dos quais se escreve atuando num ambiente imagético, ou seja, num ambiente mediado por um aparato, pela máquina.

Deixam-se impressões subjetivas em um objeto. Por meio desse ato, exterioriza-se a interioridade. Faz-se isso porque é desejável estabelecer uma ponte sobre o abismo do vazio que existe entre os sujeitos. Assim, deixar as impressões por meio do ato de inscrever numa pedra pode ser considerado uma atitude mais profunda, já que há um contato mais direto com um objeto, sem mediação. Já deixar as impressões em textos escritos à tinta é algo mais epidérmico, porque não há mais o riscar o objeto, e sim, há a sobrescrição, em que a tinta sai de um ducto com o movimento das mãos e não se faz mais tanto esforço; aliás, 
escreve-se mais assim, documenta-se mais, mas o que se lê não é tão mais contemplativo; torna-se histórico, pois o fluxo das informações torna-se maior.

Já os textos em computador e em aparelhos móveis, também como diz Boccara (2014) remetendo-se a Flusser, fazem o retorno à tarefa de contemplação, mas à contemplação de imagens, as imagens técnicas, já que se trata de imagens mediadas pela máquina; ao se contemplar imagens, parece não haver a consciência histórica que a invenção do alfabeto e o seu desenvolvimento permitiram ao longo dos séculos; há, sim, um voltar-se a um código, binário, de criação imagética técnica. De todas as formas, o meio é a mensagem: a cada progresso nas formas técnicas, a escrita adquire determinadas maneiras, e as impressões sobre a realidade vão ser escritas de formas diferentes; há milênios, em tabletes de barro; atualmente, nos tablets móveis, ou nos smartphones. De uma forma ou de outra, de forma mais profunda, de forma mais epidérmica ou de forma imagética, buscamse definir as impressões sobre o mundo, procurando estabelecer, por meio dessa escrita, uma ponte sobre os abismos entre os sujeitos.

Embora Flusser não falasse em signos, pode-se estabelecer uma relação semiótica dentro dos seus pensamentos. $O$ ato de escrever é a passagem da coisa para a não-coisa. É uma atividade que movimenta os signos. As coisas seriam os objetos referentes - os objetos ou mesmo seres nos quais as pessoas esbarram no mundo, no seu dia-a-dia -, ou significantes, que se tornam signos na tarefa escrita. Transformar coisa em não-coisa é transformar objetos de referência em signos. Com as não-coisas (signos), consegue-se a comunicação, a informação, isso numa perspectiva de comunicação humana: sair do claustro da individualidade e entrar em contato, pelos abismos, com outros seres humanos. Objetos tangíveis da realidade tornam-se, na escrita, por exemplo, narrativas, descrições, etc. A res externa torna-se res cogita: como já colocado, a escrita arranha, risca, faz talhos na matéria com a finalidade de romper a unidade da matéria para se poderem guardar experiências vivenciadas coletiva ou individualmente; quando se menciona uma imagem, rompe-se sua hipotética unidade, já que é impossível escrever mantendo a continuidade; é preciso romper, e, nesse processo, gerar os signos. As coisas tornam-se, assim, constructos semióticos: o pensamento constrói-se por signos e por imagens, já que não lhe cabem coisas ali, não lhe cabem as continuidades; os sinais gráficos (signos) devem ser alinhados por meio da sintaxe para que o pensamento organize o mundo que o rodeia.

0 pensamento trabalha por meio de imagens e de signos, portanto. Por meio da escrita, há a organização estrutural do foco, da atenção: se, ao se rasgarem as imagens, não houver retenção, a imagem rasgada vai se esvair. Há de se obedecer a uma sequência para a 
imagem não se esvair, há de se organizar uma sequência para se poder refletir, pensar, alinhar o pensamento, e, consequentemente, retê-lo. Colocam-se os pensamentos nos trilhos corretos por meio do trabalho com a escrita. Todos os objetos humanos com funções especiais são codificados em signos. Ao se escrever, conforma-se a matéria em códigos que fazem das imagens objetos operacionais no pensamento. Pela escrita, orienta-se o pensamento e, ao mesmo tempo, orienta-se a mensagem para o outro. Quando, aliás, e por exemplo, coloca-se um ponto final num texto, fecha-se um ciclo que será direcionado ao leitor por meio de uma ponte sobre o abismo de um eu em relação a outro eu: quer dizer, o outro deve procurar também significar a mensagem recebida, fazendo processar o código, fazendo a semiose progredir.

Escrever é estabelecer um processo de semiose. Escrever é, ainda, a expressão de um pensar unidimensional, já que a mente não consegue abarcar a totalidade do que existe. Escrever é expressar uma consciência histórica: quando se utiliza um código, como, por exemplo, a língua portuguesa, escreve-se considerando que esse código está inserido em um determinado contexto histórico. Quando se escreve, mostra-se que se está em um sistema coletivo de saberes e de consciência já existente.

\section{Flusser e o roteiro}

Para Flusser (2010), continuando em A escrita: há futuro para a escrita?, o roteiro e considere-se o roteiro tanto de cinema, quanto para a TV ou outras mídias - é um gênero textual que está abaixo das formas literárias. Enquanto as formas literárias advêm de um trabalho dos sujeitos que buscam a representação de uma consciência histórica, e, portanto, trata-se de um trabalho de organização de imagens naturais rasgadas para melhor apreensão do mundo, pela consciência, o roteiro é um pré-texto que não está no planalto da cultura, mas sim, num plano inclinado e escorregadio. 0 roteiro é algo subserviente ao programa técnico de filmagem. Por isso, trata-se de uma forma particular de escrita, em que a palavra passa por um processo por meio do qual ocorrem simplificações para que se ordenem ações dentro de um set.

0 roteiro, nesse aspecto, estabelece um duplo engano: simula ser um texto, mas é, de fato, um programa de imagens; simula que o alfabeto tem função na cultura das imagens, sendo que, de fato, o alfabeto vem é perdendo sua força. Nesse duplo engano, reside uma grande problemática dada pelo estudo de Flusser (2010): como há um desenvolvimento de imagens técnicas (embora ele tenha escrito o livro em 1987, suas colocações nunca 
pareceram tão atuais), diz ele que, melancolicamente, há uma forte tendência ao desaparecimento do alfabeto, ou da escrita propriamente dita. Hoje, escreve-se cada vez com menos preocupação com as regras sintáticas (especialmente por causa do universo das redes sociais, como o Facebook, o Twitter e o Instagram) e, pior, nem mais sobrescreve-se, e sim, tocam-se telas que digitalizam, no código binário, mensagens; esse ato de tocar uma tela nos distancia do trabalho da escrita propriamente dito, tornando o que se escreve uma imagem em tela, uma imagem técnica; como quase não há despendimento de energia para se trabalhar uma mensagem no universo da imagem técnica, a mensagem torna-se mais programada e pouco reflete consciência histórica.

De fato, dentro do universo das mensagens via Internet e aparelhos móveis, nota-se que essas parecem estar cada vez mais refletindo pouca consciência histórica. Essa situação reflete um contexto descrito por Lyotard (1986) de modo geral em sua obra $O$ pós-moderno: a transmissão de saber (ou de mensagens) está sendo feita pela linguagem das máquinas, e o critério de operatividade dessa transmissão de mensagens é baseado em matrizes de input/output, ou seja, na regra binária da máquina; o saber que não for traduzido para essa matriz será abandonado. 0 que obedecer a esse critério deve, pois, situar-se à lógica do melhor desempenho, para ser produzido e vendido, trocado, agregando-lhe valor mercadológico, tornando-se, enfim, mercadoria indispensável ao poderio produtivo, perdendo seu valor de uso.

Nesse contexto, a linguagem torna-se dessubstancializada, já que o saber perdeu sua substância, dando lugar à troca de informações como forma mercantil; qualquer projeto de desenvolvimento humano perde-se, dando espaço ao poder da nuvem computacional, que a tudo iguala na sua matriz de input/output. Flusser (2010), com certeza, tinha conhecimento desse contexto, e, provavelmente, via o futuro da escrita - e do ser humano - com bastante negatividade: se o ser humano obteve consciência histórica a partir do momento em que começou a escrever e assim desenvolveu sua consciência, o que esperar de uma sociedade em que haja o predomínio do tecnicismo, em que as pessoas se voltam apenas a imagens e pouco tomam contato com a leitura e a escrita?

Lewis Mumford (1980) sugere que a arte é a parte da técnica que sofre marcas da personalidade humana e que, assim, qualquer forma de arte, mesmo a mais abstrata, não é desprovida de sentido ou de marcas pessoais. Ao estudar o papel da técnica como via de manifestação do simbólico dentro da arte, Mumford (1980) auxilia a compreender o contexto atual, o qual Flusser (2012) determinava como pressionado pela existência das imagens técnicas. 
As imagens técnicas são previsíveis e prováveis, programadoras de pensamentos e comportamentos de seus espectadores, apenas informando-os do que acontece, mas não aprofundando o conhecimento sobre as coisas, sobre o mundo à sua volta. Elas programam os sujeitos, condicionando-os à repetição de matrizes, o que os torna seres a-históricos, que não reconhecem possibilidades de mudança ou transformação de realidade, visto que vivem no eterno retorno ao mesmo, ao previsível, ao programado.

Para Flusser (2010), o roteiro é um texto cuja mensagem é voltada aos aparatos técnicos. Não se dirige a editores, mas a produtores de cinema, TV e rádio e desses para espectadores, telespectadores e ouvintes. É um híbrido entre um texto para um drama a ser encenado (dramaturgia) e um programa de computador (processador Word, por exemplo), dirigido à produção de imagens técnicas. É um texto que possui aquilo que é essencial às equipes de filmagem. Para Flusser (2010), não tem carga literária: é um texto a ser filmado e esquecido. No entanto, tal ideia, de certo modo, pode ser contestada com a visão exposta pelo filósofo em $O$ universo das imagens técnicas: elogio da superficialidade (FLUSSER, 2012): pode-se operar uma transformação nessa possibilidade do roteiro, que pode construir-se tentando fissurar as próprias bases em que está assentado.

Flusser faz uma crítica à sociedade do espetáculo, que baliza a sua produção pelo viés dos interesses econômicos. Roteiristas, muitas vezes, realizam trabalhos que devem ser entregues com extrema rapidez, dentro de uma estratégia de mercado. Se se pensar na produção massiva de Hollywood ou na produção das telenovelas pela América Latina, os roteiros, na maioria das vezes, são escritos de modo a obedecerem a critérios nem sempre de interesses formativos, mas sim de necessidades de manutenção dos programas no ar. Isso não significa que não haja propostas de trabalho que façam fissuras nessa situação molar. Há diversos roteiros, nos mais variados espaços de trabalho, que propõem um escape ao padrão, de despertar o que Flusser (2012) considera como uma consciência adormecida das grandes massas.

\section{Hoje é dia de Maria: tentativa de fissurar as imagens técnicas}

Apresenta-se aqui um pequeno trecho da minissérie Hoje é dia de Maria, escrita por Luís Alberto de Abreu e Luiz Fernando Carvalho, e exibida pela Rede Globo, em 2005, como uma proposta que buscou o imprevisível. Baseada em roteiro escrito originalmente por Carlos Alberto Soffredini em 1995 (nunca produzido), a obra foi dividida no que se chamou de Jornadas: a primeira, exibida de 11 a 21 de janeiro de 2005, em oito (8) capítulos; a 
segunda, de 11 a 15 de outubro de 2005, em cinco (5) capítulos. Reuniu fábulas populares retiradas do imaginário brasileiro compiladas por pesquisadores como Mário de Andrade, Câmara Cascudo e Sílvio Romero, e os personagens atravessaram essas histórias originárias de diversas regiões do país.

Hoje é dia de Maria é um texto realizado como obra para a televisão, anos após a estreia de Luís Alberto de Abreu no cinema (com os filmes Kenoma e Narradores de Javé). É considerada uma obra

[...] original e sensível [, que] se diferencia dos padrões televisivos da cultura globalizada, extrapolando o código normativo das narrativas ficcionais e estimulando o exercício da experiência lúdica e criativa. Consegue articular o erudito e o popular, criando uma simbiose que agrega a poética das artes tecnológicas e elabora uma temporalidade distinta da televisão comercial, caracterizada pela aceleração e velocidade. (SOUZA, 2007, p. 10).

0 reconhecimento como obra de arte é inegável, haja vista o fato de fugir do convencional televisivo. Estabeleceu uma poética das tecnologias, em que a produção buscou elencar, quando da representação, elementos tecnológicos diferenciados para produzir uma noção de teatralidade ao trabalho. Construiu-se um domo, por exemplo, para que houvesse uma “[...] cenografia de 360․ Também foram pintados painéis com 10 metros de altura que ficavam ao fundo da cena e eram trocados para caracterizar novos ambientes." (SOUZA, 2007, p. 23). Tal poética permitiu, por sua vez, que se elaborasse distintamente uma temporalidade que não fizesse referência àquilo proposto pela TV comercial. 0 domo representava esteticamente o mundo de Maria e as suas emoções. A ideia de ser $360^{\circ}$, por sua vez, deu a noção de visão de mundo, já que ele é enxergado pelas pessoas, quando fora de suas casas, como um espaço circular. Somem-se a esse domo outros recursos, como o uso de câmeras parecidas às de cinema para captação das imagens, o que a diferenciava das telenovelas. Os recursos tecnológicos que puderam ser explorados na minissérie serviram para a criação e o desenvolvimento de uma poética.

Sendo o tom da minissérie farsesco, lembrando peças de teatro apresentadas em pequenos palcos em cidades do interior do país, com um quê de produção cinematográfica, tratava-se de uma obra de convergência na TV, em que tradição e tecnologia uniram-se para dar vida ao texto escrito por Luís Alberto de Abreu, em parceria com Luiz Fernando Carvalho. As imagens construídas conferiram um tom épico à narrativa proposta, o que guardava extrema relação com as propostas teatrais de Luís Alberto de Abreu. Para Abreu 
(2013), o épico é configurado por imagens, e não é à toa que o cinema é, por esse dramaturgo, considerado uma forma artística épica.

Cabem algumas palavras sobre essa criação de imagens. Luís Alberto de Abreu e Luiz Fernando Carvalho trabalham muitas vezes com personagens narradoras em suas obras, rememorando a figura do rapsodo, contador de histórias, que tece narrativas, que, por meio do texto narrado, buscam fazer o público imaginar o que está sendo contado, ou seja, criar imagens mentais. Portanto, ambos deram grande valor à forma narrativa, ao texto, dentro do universo da minissérie em questão, como forma de o elemento literário aparecer, como forma de o público trabalhar a mensagem em sua mente, como se estivesse lendo a obra.

A minissérie Hoje é dia de Maria, ao conseguir sua autenticidade num meio como o televisivo, teria sido obra-chave da convergência entre formas artísticas. Nesse contexto, o roteiro não poderia se apresentar como um mero aparato para a produção de imagens técnicas. Tome-se um pequeno trecho desse roteiro, que se transcreve abaixo, para demonstrar a possibilidade de fuga a essa molaridade:

\section{A CIDADE - PARTE II \\ CENA 1 \\ RUA/NOITE/ (PAISAGEM 1)}

O sinal de trânsito abre. Os carros avançam e buzinam com os faróis acesos em direção a DOM CHICO CHICOTE, que tenta voar com sua traquitana.

\section{NARRADORA}

'Noite! Entonce que a coisa tá nisso: inté parece feitiço, purque nada dá certo! Eita que, das veiz, a vida é deserto que põe larga distância no que parece tão perto! Vê a história de Maria: quanta peleja! Quanta agrura! Mai vamo vê se com Dom Chico Chicote e a ajuda de Deus acaba essa desventura!

Um carro abalroa DOM CHICO CHICOTE e ele cai na calçada.

\section{CENA 2}

CALÇADA AO LADO DA RODOVIÁRIA/ NOITE/ (PAISAGEM 1)

Na calçada, CHICO CHICOTE levanta-se, ajudado por MARIA. Dentro dos carros, pessoas riem de CHICO CHICOTE, gritam 'Maluco!', apupam. CHICO CHICOTE se irrita e se ofende, voltando para a rua, no meio do trânsito.

\section{DOM CHICO CHICOTE}

Incrédulos! Estava no limiar, minha pequena princesa...

Os carros passam, e o público continua a apupá-lo. 
Vendido em livrarias, o roteiro da minissérie traz todo o texto produzido pelo dramaturgo Luís Alberto de Abreu e pelo diretor de TV e cinema Luiz Fernando Carvalho (2005). 0 trecho acima pertence à Segunda Jornada, a qual conta a saga da menina Maria na cidade grande. A cena discute que a questão da tecnologia esmaga os sonhos humanos, representados por Dom Chico Chicote - personagem que, por sua vez, é representada com um livro sobre a cabeça (ABREU; CARVALHO, 2005). A cena acontece na cidade, um espaço opressor, mas vista de maneira lírica, como uma peça encenada em um palco na rua de uma pequena cidade do interior. A questão do contar algo está embutida aí: existe uma busca, pelo roteiro, de dar vida a uma narrativa, o que nos leva à intenção de uma perpetuação de uma mensagem, ainda que por via televisiva. Ora, o narrar a história pede mais atenção ao que se vê, ao que se assiste, demandando mais esforço do telespectador, que não pode simplesmente orientar-se pela construção de diálogos como os da telenovela.

0 pequeno trecho, ainda, para ser absorvido em sua complexidade, exige do espectador que pelo menos busque compreender a frase "[...] tudo o que é sólido se desmancha no ar!" (ABREU; CARVALHO, 2005, p. 453), dentro do contexto da trama apresentada. 0 que sugere? Dentro do contexto da Segunda Jornada da minissérie, Chico Chicote é uma personagem que procura colocar que as pessoas perderam a capacidade de sonhar (ABREU; CARVALHO, 2005). No trecho em questão, Chicote está tentando voar com sua traquitana, uma metáfora para a capacidade humana de voar alto com seus sonhos e projetar uma vida diferente (ABREU; CARVALHO, 2005). O sólido - a vida como está, a rotina que muitos acreditam ser imutável, ser impossível alterar-se - pode se desmanchar a qualquer momento, caso algo inesperado aconteça - é a mensagem de Chicote, de que tudo pode desmanchar-se no ar, ou seja, alterar-se, modificar-se (ABREU; CARVALHO, 2005). Nesse raciocínio, Chicote apregoa que não se pode ficar preso a esquemas molares prontos, enrijecedores, e sim, é preciso estar aberto, é preciso fissurar os esquemas molares e deixarse enriquecer de novas experiências nas relações de si com o outro, com o mundo, e mesmo na relação consigo próprio (ABREU; CARVALHO, 2005). Ou seja, dentro do próprio texto, sugere-se a quebra da previsibilidade, daquilo que é programado, tal como proposto por Flusser.

Para os mais conhecedores, a frase faz referência ao título do livro do filósofo estadunidense Marshall Berman (1986), Tudo o que é sólido desmancha no ar: a aventura da modernidade, que, por sua vez, é uma frase retirada do Manifesto comunista, de Marx e Engels. A frase dita por Chicote semiotiza a minissérie para outros meandros, além do próprio contexto da trama. Nesse sentido, o subtexto parece querer explorar uma leitura da 
trama para além do contexto dado pelo audiovisual. Ainda que a exibição de uma cena dessas seja feita no ambiente televisivo, em que o tempo das cenas raramente é distendido, não dando espaço para o público refletir sobre o que vê, o roteiro parece convidar à reflexão sobre o próprio modelo de sociedade em que está inserido, sociedade essa moldada - pelo menos à época da exibição, já que houve uma explosão de tecnologias - pela televisão, cujas exibições de programas, telejornais e propagandas apenas reiteram os valores do capitalismo neoliberal. Na minissérie, Chicote é um artista, um artesão à la Leonardo da Vinci, mas quixotesco, em sua busca contra os moldes sociais estabelecidos (ABREU; CARVALHO, 2005).

O que a frase replica, então, a partir do contexto da minissérie, em relação ao texto de Berman (1986)? O filósofo revisita o texto do Manifesto comunista de Marx e Engels, no qual ambos sugerem que todas as relações dos homens com o mundo que o rodeia não conseguem se solidificar, tornando-se este o paradigma da sociedade contemporânea: a promessa do industrialismo e da lógica do neoliberalismo promete sucesso na vida ao mesmo tempo em que delimita uma tênue linha entre essas promessas e a destruição das mesmas pelas constantes crises engendradas pelo próprio sistema. Como dizem Marx e Engels (2001),

\begin{abstract}
Essa subversão contínua da produção, esse abalo constante de todo o sistema social, essa agitação permanente e essa falta de segurança distinguem a época burguesa de todas as precedentes. Dissolvem-se todas as relações sociais antigas e cristalizadas, com seu cortejo de concepções e de idéias secularmente veneradas; as relações que as substituem tornamse antiquadas antes de se consolidarem. Tudo que era sólido e estável se desmancha no ar, tudo o que era sagrado é profanado e os homens são obrigados finalmente a encarar sem ilusões a sua posição social e as suas relações com os outros homens. (MARX; ENGELS, 2005, p. 43).
\end{abstract}

Chico Chicote grita à menina que está no limiar (ABREU; CARVALHO, 2005, p. 453); pode-se perceber uma compreensão da personagem de estar nessa tênue linha. Não é estranho, nesse contexto, as pessoas sentirem uma grande sensação de insegurança, que suas relações interpessoais não se pautam pela confiança no outro, que estão desorientadas ou desesperadas, numa sensação constante, como diz o trecho acima, de agitação e de falta de segurança. Nesse paradigma marcado pela dialética construção-destruição, os donos do poder mundial estabelecem seus jogos de guerra para manter o poder sobre as populações de seus países e para avançarem sobre outros. Aí se insere a guerra na minissérie, preconizada nas palavras de Chicote; daí o texto, com apuro formal, semiotizando uma 
mensagem com mais fissuras, com mais espaços reflexivos. Chicote mostra que deseja que o contexto se modifique, que os sujeitos voltem a sonhar para modificar sua realidade, que acordem para possíveis alterações no seu modus vivendi. Ou seja, Chicote grita, procurando despertar consciências entorpecidas; não é ouvido pelas outras personagens, mas sua mensagem é veiculada pelos mesmos feixes de raios sincronizados que irradiam mensagens entorpecentes e automatizantes, como se vê dito em Flusser.

A narradora, por sua vez, parece ser uma voz estranha no roteiro, o que não é uma verdade. Ela representa a polaridade popular dentro da articulação poética do texto da minissérie, em relação ao polo erudito. Sua fala apresenta elementos da linguagem inspirados na comunicação de uma comunidade mais rural, própria do interior de São Paulo. A maioria das palavras apresenta modificações em relação ao português padrão. A minissérie busca a narratividade em elementos da oralidade como forma de acessar caracteres da ancestralidade. Nos estudos da linguagem, a oralidade é uma variante linguística que está ligada ao relato, à narrativa. Marcuschi (2014) vai dizer que

A noção de oralidade está estreitamente relacionada ao uso da modalidade oral da língua em práticas sociais e discursivas, tanto no que se refere à sua produção, quanto no que diz respeito à sua escuta. Envolve a ação de linguagem de sujeitos ativos e responsivos em contextos interacionais diversos (públicos ou privados) e registros de linguagem variados (formais ou informais). A oralidade não se restringe ao estudo da materialidade da fala, mas envolve, em contextos socioculturais específicos, a fala associada a seu ritmo, entonação, volume e entrelaçada a múltiplas linguagens, como a gestualidade, a mímica, a imagem e até à modalidade escrita da língua (por exemplo, na TV, numa exposição oral em que se usa algum apoio escrito). Mesmo quando um indivíduo não se manifesta verbalmente, suas reações corporais (de interesse, curiosidade, tédio, indiferença, cansaço, emoção, entre outras) podem influenciar nas decisões discursivas tomadas por seu(s) interlocutor(es) e, com isso, no andamento da interação. (MARCUSCHI, 2014, não paginado).

Na minissérie, predominam escolhas linguísticas de uma cultura não erudita, com ritmo e entonação diferenciados do padrão visto na TV. São falas que revelam traços, aliás, relacionados à ancestralidade do idioma, retomadas por Abreu e Carvalho do roteiro de 1995, escrito por Carlos Alberto Soffredini:

Soffredini estudou o caipira a partir de obras antropológicas, sociológicas, filológicas e literárias. Entretanto, a obra dramatúrgica resultante destes estudos não procurou ser um registro narrativo das tradições do universo caipira. Mais profundo, o texto [de Na carrêra do divino] constrói-se a partir do conflito altamente destrutivo que as relações capitalistas 
trouxeram para o trabalhador rural. Ao migrar do campo para a cidade, em busca da salvação, a protagônica família de caipiras encontrará o aniquilamento, [se não] o próprio, ao menos o de sua cultura, o que denota o sentido trágico da peça (e do processo social em si). (PINTO, 2015, p. 62).

Soffredini (S. d.) iniciou, com sua peça $\mathrm{Na}$ carrêra do divino, um estudo sobre a linguagem do caipira, partindo de diversas fontes de estudo. Uma delas foi $O$ dialeto caipira, de Amadeu Amaral (1920), em que o autor faz um grande apanhado linguístico de pronúncia, de fonética, de fonemas e de léxico do falar caipira. Esse apanhado fez parte dos estudos de Soffredini para a construção de sua obra teatral. Amaral (1920) define o caipira como um roceiro ignorante e atrasado, numa visão um tanto quanto preconceituosa, a mesma, talvez, que Monteiro Lobato apresentava quando criou Jeca Tatu. Para Soffredini (2017), no entanto, com o crescimento do estado de São Paulo, com o desenvolvimento de centros populares cada vez maiores, com redes de comunicação e com a expansão do sistema educacional, as províncias passam a se abrir mais com a civilização exterior. Esse aspecto, no entanto, tornou-se um problema, já que muitos caipiras se viram marginalizados na vida coletiva, o que é denunciado por Soffredini (S. d.) em Na carrêra do divino. 0 estudo da obra de Amaral, nesse sentido, busca as raízes do dialeto caipira como uma forma de reencontrar-se com um aspecto cultural típico do estado de São Paulo, com características ancestrais da língua portuguesa, mas procurando criticar o conteúdo que o autor expressa.

O dialeto caipira é um componente forte do roteiro de Hoje é dia de Maria (ABREU; CARVALHO, 2005), já que remonta à linguagem popular estudada por Soffredini (S. d.), pois tinha a intenção de trazer o universo popular à cena. É um componente poético que estrutura o roteiro. Foi, assim, fartamente ampliado na minissérie por Luís Alberto de Abreu e Luiz Fernando Carvalho (2005). Inclusive marcas da fala comum popular são levadas em consideração. Amadeu Amaral (1920) estuda a linguagem caipira de modo a descrever a forma como as palavras se alteram. 0 trabalho é linguístico-filológico. Alguns exemplos presentes no texto do roteiro da minissérie (ABREU; CARVALHO, 2005): entonce (termo do antigo latim vulgar, formado pela preposição in e pelo advérbio arcaico tunce, este sendo o equivalente ao então do português; a palavra é um arcaísmo utilizado no texto da minissérie), tá (supressão de sílaba inicial), inté (como forma de até) é a junção de então, que vira geralmente intão - pois a nasalização do /e/ inicial torna-o um /i/ - com o até), veiz (quando o $s$ pluralizador vem precedido de vogal a que se apoia, desaparece também esta), mai (do som /s/ em mas, que ganha um /i/, ficando mai - o mesmo ocorrendo em outros trechos com o faz, que se torna fai; esses elementos sofrem o que se chama de 
ditongação). $O$ dialeto caipira (AMARAL, 1920) é um componente cujo estudo de expressões foi amplamente levado em consideração no roteiro de Hoje é dia de Maria (ABREU; CARVALHO, 2005), já que remonta à linguagem popular, pois tinha a intenção de trazer o universo popular à cena. É um componente poético que estrutura o roteiro.

A linguagem falada é repleta de pausas, de reticências, de trechos sem ligação sintática, daí a sua possibilidade de expansão de significados - não é à toa que houve a evolução das línguas na história da humanidade; a linguagem falada é que promoveu essa evolução, emprestando termos, deixando de lado expressões fora de contexto, adaptando o que fosse preciso para os diferentes momentos da história dos homens. Quando se estuda linguagem popular, deve-se levar em consideração esses aspectos na produção da obra artística. Se a linguagem popular consegue entrever essa possibilidade de expandir significações ${ }^{1}$, a obra que nela se apoiar também poderá abrir-se a essa possibilidade. Nesse aspecto, a linguagem popular se mostra espaço para a construção de uma poética riquíssima de sentidos. Essa poética é aspecto constitutivo da minissérie Hoje é dia de Maria.

Luís Alberto de Abreu é considerado um artesão de palavras. Sua obra teatral remete-se ao universo popular, à cultura popular, e narra histórias baseadas em contos de fadas (Auto da infância), em narrativas bíblicas (O Livro de Jó), em canções populares (Um dia ouvi a Lua). Também escritor de roteiros cinematográficos (Kenoma e Narradores de Javé), na TV, junto a Luiz Fernando Carvalho, Abreu desenvolveu obras de cunho diferenciado (além de Hoje é dia de Maria, A pedra do reino e Capitu). Já Carvalho é um diretor artífice das imagens, ainda que imagens técnicas, mas imagens que buscam a direção contrária aos padrões irradiados pelos media. Sua obra televisiva abrange trabalhos grandiosos que estão longe do que comumente se vê na TV, tencionando menos dispersão do pensamento do espectador. Com Hoje é dia de Maria, escrito com Abreu, ele se vale do fio narrativo da infância, já evidente em Abreu em sua peça Auto da infância, para falar da ancestralidade; para ele, esta é

[...] algo que nos permite imaginar mais que copiar. Sentir mais que descrever e explicar. A ancestralidade é uma metáfora acessível a todos nós e que deve, assim como hoje se faz com os bíceps, ser exercitada. A ancestralidade transpassa fronteiras e, inexplicavelmente, como ela só, uniu João Cabral a Sevilha, João Gilberto ao jazz, Ariano Suassuna a Cervantes. A ancestralidade é o que há de mais moderno e ao mesmo tempo mais arcaico. Está presente nas pesquisas mais avançadas da ciência, no Genoma humano, nas células-tronco. Tudo se reflete na

${ }^{1}$ A linguagem culta também permite essa possibilidade, obviamente. Está-se falando da linguagem popular por ser o tópico de debate neste momento. 
ancestralidade, seja ela biológica ou espiritual. (CARVALHO, 2006, não paginado).

A relação do diretor da minissérie com a produção do roteiro, escrita por ele e por Luís Alberto de Abreu produz um texto que extrapola o discurso midiático padrão. 0 roteiro de Hoje é dia de Maria (ABREU; CARVALHO, 2005) vale-se de elementos que se propõem a fissurar o padrão. Ao Carvalho (2006) mencionar que o objetivo maior da minissérie é falar da ancestralidade por meio de uma narrativa em que a infância é discutida, sugere tratarse de uma obra que provoca estranhamentos, tencionando uma reprogramação do que é irradiado, em acordo àquilo que mencionou Flusser (2012) em $O$ universo das imagens técnicas: elogio da superficialidade. A própria última fala transcrita de Dom Chico Chicote, "Um dia mostro a vocês que tudo o que é sólido se desmancha no ar!" (ABREU; CARVALHO, 2005, p. 453), traz um caráter diferenciado: ela não é explicada na cena em questão, ela traz apenas uma sugestão a respeito da fugacidade das coisas, de uma realidade que se esvai rapidamente. Não é à toa que Chico Chicote, na minissérie, tem um livro sobre a cabeça: histórias sem fim podem ser contadas por aqueles cavaleiros andantes que sonham; mas no universo tecnicista, esses cavaleiros andantes são vistos como loucos, ou doentes mentais, ou como um perigo, daí a crueldade com que ele é tratado pelos motoristas e é atropelado.

\section{Pequena conclusão}

Roteiros, segundo Vilém Flusser (2010), são formas intermediárias entre imagem e escrita. Boa parte desses textos é conformada para servir ao programa técnico de filmagem, sendo, assim, de modo geral, esquemas de programas os quais, por sua vez, formarão massas ligadas a aparatos técnicos. Nesse contexto, de modo geral, não importa o que as imagens mostram, e sim, o modo como elas irão programar os sujeitos. Esses sujeitos, nesse contexto, apenas apreenderão o real como espetáculo, não analisável, mas consumível.

Boa parte dos roteiros, assim, nesse pressuposto de Flusser (2010) em A escrita: há futuro para a escrita?, é programada a condicionar sujeitos a-históricos, pouco reflexivos sobre as relações de causa e consequência entre os fatos, já que podem ser manipulados segundo essa ou aquela orientação, bem como descontextualizados e espetacularizados. Como muitos espectadores já nem realizam atividades de leitura e de escrita, somente se pautando pelas imagens dos media, pouco organizam as questões sobre a realidade em seu pensamento. Como boa parte dos roteiros é, como Flusser (2010) diz, programadora de 
pensamentos e comportamentos, não são elementos que permitem com que se ordene o pensamento, apenas elementos criadores de imagens, as quais ele chamou de técnicas (FLUSSER, 2012).

Mas há como se contrapor a essa realidade programadora, que é, como o próprio Flusser (2012) sugere em $O$ universo das imagens técnicas: elogio da superficialidade, atacar os feixes sincronizados, os fascismos, tecendo fios transversais antifascistas, uma forma de engajamento politizador dentro da própria rede. Por vezes, ocorrem tentativas de se buscar a orientação do pensamento e de se orientar a mensagem que é enviada para o outro com um sentido que provoque uma quebra nessa programação. 0 trecho do roteiro de Hoje é dia de Maria (ABREU; CARVALHO, 2005, p. 453), exposto neste trabalho, buscou demonstrar que há artistas, como Luís Alberto de Abreu, com sua experiência na dramaturgia, e Luiz Fernando Carvalho, um grande artífice da direção de obras cinematográficas e televisivas, que se engajam politicamente contra a dispersão do público, tecendo fios transversais, ou antifascistas, que questionam os eixos centrais transcodificadores de mensagens à grande massa.

A minissérie em questão trata-se de um produto televisivo que extrapolou o que é comumente irradiado pela mídia televisiva. 0 pequeno trecho transcrito é retrato de um todo que provoca estranhamentos. Nesse trecho, apresenta-se uma mensagem baseada em um conceito filosófico, a frase de Marshall Berman (1986) que alude ao Manifesto comunista; apresenta-se, também, uma construção poética que se vale do dialeto caipira, em um pequeno texto dito pela narradora, que, como um rapsodo, tecia a narrativa e permitia ao público uma forma de acessar novamente a imaginação criadora. Além disso, a minissérie como um todo fugiu ao que é comum nos produtos de entretenimento televisivo padrão: fora filmada em um cenário fechado, com painéis pintados, em um domo, como um circo; foram utilizadas câmeras de cinema, algo difícil na TV em, 2005; ainda, a atuação era farsesca, diferenciada do que se vê comumente na TV. Por fim, o roteiro foi vendido em livrarias, figurando-se como um produto também a ser lido, apreciado via outra mídia.

Há, assim, um viés de engajamento político quando se avalia a questão desse roteiro, questionando as formas audiovisuais programadoras e previsíveis: provocando estranhamento, provoca a aparição do imprevisível. Esse engajamento não nega a produção imagética, e sim, vale-se dela, algo pressuposto na escrita do roteiro, como uma provocação ao espectador passivo, uma reprogramação desse espectador acostumado a esquemas já programados: convida-o a estranhar, passo importante para refletir sobre a imagem que se lhe afigura. 


\section{Referências}

ABREU, Luís Alberto de; CARVALHO, Luiz Fernando. Hoje é dia de Maria. São Paulo: Globo, 2005.

ABREU, Luís Alberto de. Território expandido. [S. l.: s. n.], 2013. 1 vídeo (ca. 52 min).

Publicado pelo canal SP Escola de Teatro.

AMARAL, Amadeu. 0 dialeto caipira. [S. l.: s. n.], 1920.

BERMAN, Marshall. Tudo que é sólido desmancha no ar: a aventura da modernidade. São Paulo: Companhia das Letras, 1986.

BOCCARA, Ernesto Giovanni. [Correspondência]. Destinatário: Luís Roberto Arthur de Faria. [S. l.], 21 out. 2014. 1 email.

CARVALHO, Luiz Fernando. Sobre a Primeira Jornada. In: HOJE é dia de Maria. Direção: Luiz Fernando Carvalho. [Brasil]: Globo Marcas, 2006. 3 DVDs (606 min), color.

FLUSSER, Vilém. A escrita: há futuro para a escrita? São Paulo: Annablume, 2010.

FLUSSER, Vilém. 0 universo das imagens técnicas: elogio da superficialidade. [S. l.]: Annablume; Imprensa da Universidade de Coimbra, 2012.

LYOTARD, Jean François. 0 pós-moderno. Rio de Janeiro: José Olympio, 1986.

MARCUSCHI, Beth. Oralidade. In: Glossário Ceale: termos de alfabetização, leitura e escrita para educadores. [S. l.]: UFMG, 2014.

MARX, Karl; ENGELS, Friedrich. Manifesto do partido comunista. $1^{\underline{a}}$ edição, $4^{\underline{a}}$ reimpressão. São Paulo: Boitempo Editorial, 2005.

MUMFORD, Lewis. Arte e técnica. São Paulo: Livraria Martins Fontes, 1980.

PINTO, Maria Emília Tortorella Nogueira. 0 popular no moderno teatro brasileiro: das projeções de Alcântara Machado às realizações de Carlos Alberto Soffredini. 2015.

Dissertação (Mestrado em Artes da Cena) - Programa de Pós-Graduação em Artes da Cena, Universidade Estadual de Campinas, Campinas, 2015.

SOFFREDINI, Carlos Alberto. Na carrêra do divino. Cópia doada ao Laboratório de Textos do Departamento de Artes Cênicas da UNICAMP pelo Professor Adilson de Barros, em Novembro de 1985.

SOUZA, Nadine Helena Diel de. “Hoje é dia de Maria” Inovação e intertextualidade na linguagem televisiva. 2007. Trabalho de Conclusão de Curso (Bacharelado em Comunicação Social) - Faculdade de Ciências Sociais Aplicadas, Centro Universitário de Brasília, Brasília, 2007. 


\title{
A note about the view of Vilém Flusser on screenwriting before the miniseries Today is \\ Maria's day
}

\begin{abstract}
Based on two works by Vilém Flusser, A escrita: há futuro para a escrita? (2010) and O universo das imagens técnicas (2012), this article discusses the production of screenplays from the perspective of the philosopher on writing and the creation of technical images. As these two works of Flusser can indicate, screenplays can compose a textual genre focuses on programming people's thinking and conducting. This article shows a piece of the script of the miniseries Today is Maria's day [Hoje é dia de Maria] (2005) as a possibility of escape of this programming disposition. This miniseries was written by Luís Alberto de Abreu and Luiz Fernando Carvalho from an original script written by Carlos Alberto Soffredini. By facing the piece of the referred script with the perspective of the philosopher on writing, along with the creation of technical images, this article shows the possibility of screenplays being a television's media text that transcends the disposition of programming people. Screenplays can therefore reprogram people. Screenplays can provoke a look of strangeness thus making people think about what they read or watch.
\end{abstract}

\section{Keywords}

Flusser. Screenplay. Writing. Miniseries. Today is Maria's day.

Recebido em 26/03/2020

Aceito em 23/07/2020 